\title{
'Stun gun' link to Raynaud's syndrome unconvincing
}

\author{
Donald Dawes, Mike Brave
}

\section{To the Editor,}

We read with interest the case report 'Frequent use of stun gun may be associated with vibration-induced Raynaud's phenomenon: A case series' in which the authors report four cases of Raynaud's syndrome which they postulated may be related to repeated use of a 'stun gun' [1]. Unfortunately, this case report suffers from too many flaws to even propose such a link. They did not report the type of 'stun gun' used by the four patients, however, since they reference literature on TASER ${ }^{\circledR}$ conducted electrical weapons (CEW), we will assume, for the purpose of this letter, that they are implicating these weapons.

\section{RESPONSE TO CASE REPORT}

"Vibration white finger" was described originally by Dr. A. Hamilton of Harvard in Indiana rock drillers. Since that time, other vibration-producing tools such as gas-powered chain saws, rock drills, grinders, riveters, pneumatic hammers, and jackhammers have been implicated [2]. According to a review by Heaver et al., the risk is greatest in occupations using pneumatic drills, grinders and impact wrenches [3]. Vibration is measured in $\mathrm{m} / \mathrm{s}^{2}$ (an acceleration). As there are no moving parts in the TASER CEW, there is no acceleration. The CEW produces pulses of electricity and the electricity does not feedback to the user through the handle. Interestingly,

Donald Dawes ${ }^{1}$, Mike Brave ${ }^{2}$

Affiliations: ${ }^{1} \mathrm{MD}$, FACEP, FAAEM, Lompoc Valley Medical Center, Lompoc, CA, USA; 2 JD, LAAW International, LLC, Scottsdale, AZ.

Corresponding Author: Donald M. Dawes, MD, FACEP, Clinical Attending, Lompoc Valley Medical Center, 1515 East Ocean Avenue, Lompoc, CA 93436, USA; Ph: 805-4524574; Email: donalddawes@gmail.com

Received: 17 January 2014

Accepted: 09 April 2014

Published: 01 June 2014 according to Heaver et al., the "dominant" frequencies of vibration for damage are between 25 and $320 \mathrm{~Hz}$ [3]. The TASER X26 produces electrical pulses at $19 \mathrm{~Hz}$. There may be a minimally perceived vibration if the CEW is arced, where the current passes between the two metal electrodes on the front of the CEW, due to pressure from the heating of the air. But, again, as anyone who has fired one of these CEWs, it is barely perceptible, and certainly orders of magnitude different from the tools implicated in the development of this syndrome.

The authors did not report the frequency of use in the patients. An average of 1-2 h/day of use of vibrationproducing tools has been considered sufficient to provoke this syndrome although it depends on the degree of vibration [2]. A typical law enforcement user would test fire the CEW for a second or two perhaps once a shift. Actual field use would be very infrequent. In an analysis by Brewer and Kroll, each CEW was used 0.550 times per year [4], and exposures over 5-10 seconds per use would be very uncommon. Several studies have shown $80 \%$ of field exposures to be 10 seconds or less $[5,6]$. What is especially remarkable is that for three of the patients, the "exposure time" was 1-3 months. So, if, on average, a CEW is used 0.550 times per year, and these patients developed the syndrome from one month to three months (three patients) after first using the CEW, it would be very unusual for there to be much use in that timeline. It is just not compelling that this infrequent use in such a short time would create a syndrome which has mostly been described in daily users of several hours per day of highenergy vibration-producing tools. ISO 5349 contains curves that show the predicted effect for a given vibration exposure over time. For example, at $5 \mathrm{~m} / \mathrm{s}^{2}$, the vibration in a grinder, for $4 \mathrm{~h} /$ day, it would take five years for $10 \%$ of exposed workers to develop Stage 1 symptoms [7].

While we would give the authors the benefit of the doubt on the actual diagnosis, it is important to realize that there is overlap in clinical features, specifically the neurologic, between secondary Raynaud's syndrome and other repetitive use syndromes that at least some of the patients may have been at risk for (e.g., carpal tunnel neuropathy from daily typing into an in-car data terminal). There is also a background risk of primary Raynaud's in the general population. In addition, it is 
not clear they adequately assessed the patients for other activities that might lead to secondary Raynaud's. Two of the patients were sellers, and care of weapons systems, could involve vibration-causing tools.

It is also interesting that both hands were affected in three of the four patients. This is interesting since the CEW can be fired one-handed due to its lightweight (and most test firings would be one-handed); and, even if fired two-handed, the second hand would be used as a support hand and would have minimal contact with the CEW itself. They claim symptoms were predominant in one hand, but they did not indicate if this was the "strong hand" for the patients. The authors also fail to identify other important historical aspects such as how the patients were identified, which does not help the reader understand the biases that may have been introduced.

They report stoppage, as well as medications, alleviated the symptoms. It is hard to know if the stoppage of the 'stun gun' alone would have led to a symptom amelioration, which would have made for a stronger argument because there were several changes. Although even here, a placebo effect, with subjective reporting and so few patients, would be hard to exclude.

So, the authors report of only four cases, are not specific about the 'stun guns' used, present a very incomplete case, and 'lump' occasional, brief use of an non-vibrating device to daily, prolonged use of high energy tools. This case report presents a wholly unconvincing argument.

\section{How to cite this article}

Dawes D, Brave M. 'Stun gun' link to Raynaud's syndrome unconvincing. Int $\mathrm{J}$ Case Rep Images 2014;5(6):465-467.

doi:10.5348/ijcri-201454-LE-10014

\section{Copyright}

(C) 2014 Donald Dawes et al. This article is distributed under the terms of Creative Commons Attribution License which permits unrestricted use, distribution and reproduction in any medium provided the original author(s) and original publisher are properly credited. Please see the copyright policy on the journal website for more information.

\section{REFERENCES}

1. Ghaheri H, Karimi M, Assari S. Frequent use of stun gun may be associated with vibration-induced Raynaud's phenomenon: A case series. International Journal of Case Reports and Images 2014;5(2):95-8.

2. Cherniack MG. Raynaud's phenomenon of occupational origin. Arch Intern Med 1990;150(3):519-22.

3. Heaver C, Goonetilleke KS, Ferguson H, Shiralkar S. Hand-arm vibration syndrome: A common occupational hazard in industrialized countries. J Hand Surg Eur Vol 2011;36(5):354-63.

4. Brewer JE, Kroll MW. Chapter 24: Field Statistics Overview. pg 285. TASER $\AA$ Electronic Control Devices: Physiology, Pathology, and Law, by Mark W. Kroll (Editor), JeffreyD. Ho (Editor), Springer 2009.

5. Bozeman WP, Hauda WE 2nd, Heck JJ, Graham DD Jr, Martin BP, Winslow JE. Safety and injury profile of conducted electrical weapons used by law enforcement officers against criminal suspects. Ann Emerg Med 2009;53(4):480-9.

6. Strote J, Walsh M, Angelidis M, Basta A, Hutson HR. Conducted electrical weapon use by law enforcement: An evaluation of safety and injury. J Trauma 2010;68(5):1239-46.

7. Canadian Centre for Occupational Health and Safety: Vibration - measurement, control and standardsat http://www.ccohs.ca/oshanswers/phys_agents/ vibration/vibration_measure.html. Accessed 1/6/14.

\section{Author Contributions}

Donald Dawes - Substantial contributions to conception and design, Acquisition of data, Analysis and interpretation of data, Drafting the article, Revising it critically for important intellectual content, Final approval of the version to be published

Mike Brave - Analysis and interpretation of data, Revising it critically for important intellectual content, Final approval of the version to be published

\section{Guarantor}

The corresponding author is the guarantor of submission.

\section{Conflict of Interest}

Authors declare no conflict of interest. 


\section{ABOUT THE AUTHORS}

Article citation: Dawes D, Brave M. 'Stun gun' link to Raynaud's syndrome unconvincing. Int J Case Rep Images 2014;5(6):465-467.

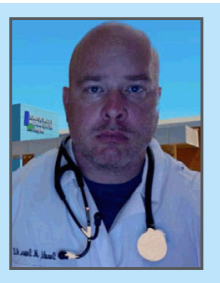

Donald Dawes is a board-certified emergency medicine physician practicing at Lompoc Valley Medical Center in California. He is also a consultant to TASER International, and a reserve police officer. His research interests include conducted electrical weapons, arrest physiology, and excited delirium. He has dozens of published peer reviewed papers in these areas.

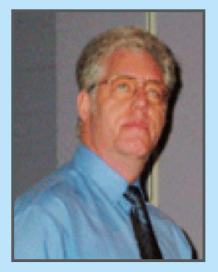

Michael Brave is a nationally recognized law enforcement use-of-force consultant, trainer and expert. He serves as National/International Litigation Counsel for TASER International, Inc., and Legal Advisor to the TASER Scientific and Medical Advisory Board and the TASER Training Board, and is a Master TASER Conducted Electrical Weapons Instructor. He also serves as Legal Advisor to the International Law Enforcement Educators and Trainers Association.

Access full text article on other devices

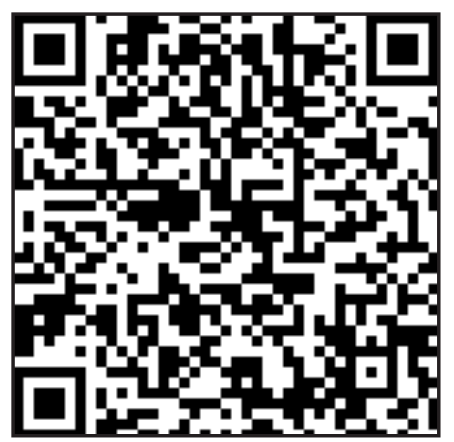

Access PDF of article on other devices

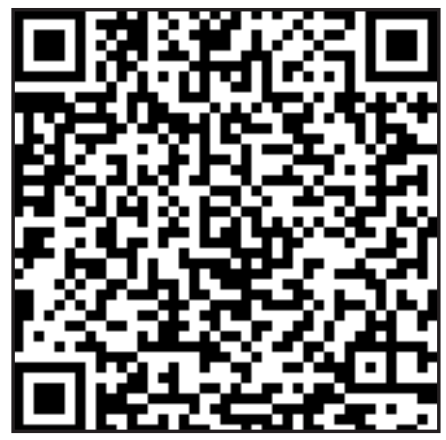

